\title{
Photonic and Optoelectronic Devices Based on Mesoscopic Thin Films
}

\author{
Kuppuswamy Kalyanasundaram, Shaik M. Zakeeruddin, and Michael Grätzel*
}

\begin{abstract}
Dye-sensitized solar cells (DSCs) are one of the most promising environmental friendly and low material costs photovoltaic devices. DSCs accomplish the separation of the optical absorption and charge separation processes by the association of a sensitizer as light absorbing material with a wide band gap semiconductor. The mesoscopic morphology of the semiconductor produces an interface with a huge area endowing these systems with intriguing optoelectronic properties. In recent years the DSC has made excellent progress. Conversion efficiencies over $12 \%$ and excellent stability have been reached rendering it a credible alternative to conventional p-n junction photovoltaic devices. Commercial exploitation of DSCs started in 2009. In addition to the DSC, Laboratory of Photonics and Interfaces performs research in the field of photoelectrochemical water splitting and materials design for organic light emitting diodes.
\end{abstract}

Keywords: Dye-sensitized solar cells · Organic Light emitting diodes · Photochemical water splitting

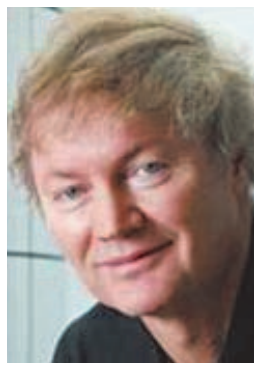

Photochemical conversion and storage of solar energy has been the primary theme of research in the Laboratory for Photonics and Interfaces (LPI) for several decades. The primary challenge here has been control of light-induced electron transfer reactions. Organization of reactants at microscopic level and ability to modulate electron transfer rates are essential for the design of efficient energy conversion and storage devices. Earlier studies focused on possible use of microheterogeneous systems of various kinds such as micelles, vesicles, polyelectrolytes and colloidal semiconductors. Studies of interfacial electron transfer process in colloidal and particulate semiconductor systems indicated several avenues for optimization of key electron transfer steps. These earlier studies have led to a systematic examination of mesoporous films of semiconducting oxides as substrates for photonic and optoelectronic devices.

Advances in sol-gel and other template-based synthetic methods along with development of experimental techniques for the characterization of device structure and quantification of the processes permit a bottom-up approach for the design of efficient thin-film devices. Thin-film devices such as photovoltaic solar cells, batteries, luminescence sensors, electrochromic and photochromic displays are some of the candidates examined in depth in our laboratory over two decades. In the following paragraphs a brief description of the key principles of operation of these devices and their present state of the art are given.

\section{Dye Sensitized Solar Cells}

Fig. 1 shows schematically the design and operational principles of a dye-sensitized solar cell, abbreviated herein simply as DSC. It is a sandwich structure wherein the anode and cathodes are separated by organic electrolyte. The heart of the device is the photoanode composed of few micron thick oxide layers prepared using nanosized colloidal particles of a wide bandgap semiconductor such as $\mathrm{TiO}_{2}$. The enormous surface area available in these mesoscopic films permit deposition of dye molecules sufficient to absorb quantitatively photons of solar radiation in a monolayer fashion. Upon optical excitation, the dye injects an electron into the conduction band of the semiconductor and is subsequently regenerated back to the ground state by electron donors present in the electrolyte. The injected electrons

${ }^{*}$ Correspondence: Prof. M. Grätzel

Laboratory for Photonics and Interfaces

Institute of Chemical Sciences and Engineering

School of Basic Sciences, Swiss Federal Institute of

Technology

$\mathrm{CH}-1015$ Lausanne

Fax: +41216936100

E-mail: michael.graetzel@epfl.ch

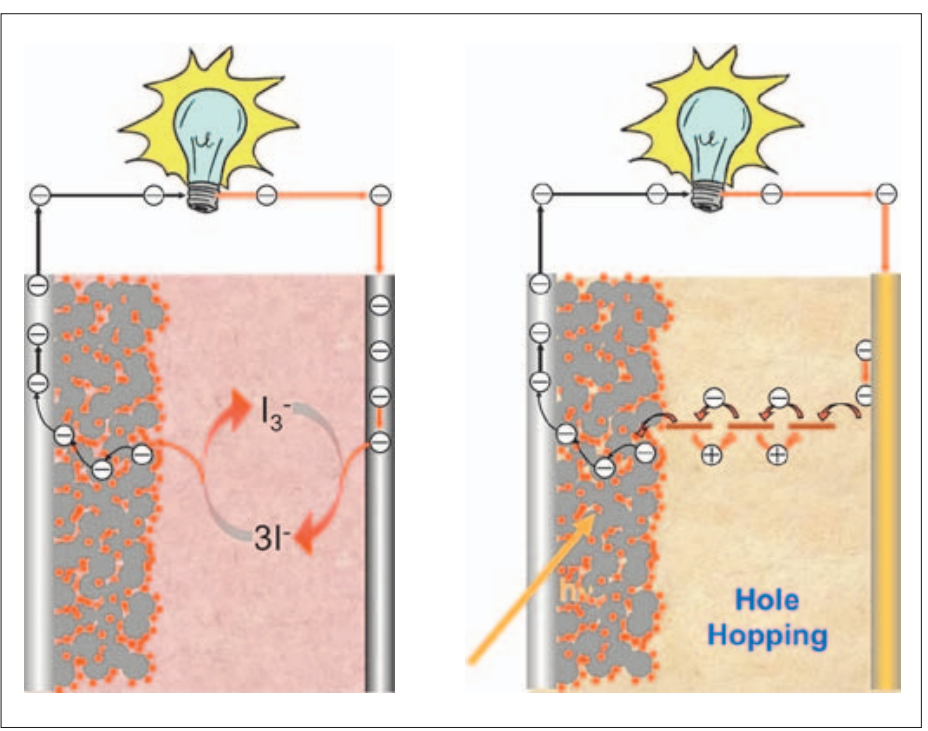

Fig. 1. 
percolate through the mesoporous film to reach the back collector electrode. Taking these electrons through an external circuit permits regeneration of the oxidized form of the donor at the counter electrode. Thus the sandwich structure of the solar cell permits continuous conversion of visible light absorbed by the dye molecules directly to electricity, regenerating all the key components in a cyclical fashion.

The spectral response of the solar cell will depend on the absorption spectral features of the dye. The maximum photocurrent obtainable is determined by the absorption threshold and the magnitude of light absorption (molar absorbance) of the dye. The difference in the energy levels of the electron acceptor (chemical potential or Fermi level of the conduction band of the semiconductor) and the organic electrolyte gives the maximum photovoltage that one can draw from the device. A mixture of iodine and iodide in a low viscosity solvent is widely used as the redox electrolyte, although other mediators such as $\mathrm{Co}$ (II)/Co(III) complexes, sulfide/ dithiolates, chalcogenides and TEMPO appear promising as alternatives. The inherent design features of the DSC (photoinduced electron transfer taking place at an interface with the conduction band of the semiconductor as electron acceptor) provide considerable leverage in controlling the electron recombination dynamics. A variant of this liquid electrolyte-based DSC is one where a second organic hole transport material HTM is spin-coated onto the oxide layer after the deposition of the dye. The counter electrode is subsequently added as a gold finger over the film. The advantage of such a solid-state version of DSC is possible packaging in the form of lighter weight portable solar cells.

During the last two decades considerable research effort has been expended to develop efficient candidates for all the key components: photoanode, light-absorbing dye, redox mediator with associated electrolyte(s) and counter electrode. During the last decade there has been a steep rise in the number of laboratories working on DSCs. Over 4000 research publications have appeared. Dye solar cell efficiencies (independently certified by standardization agencies) have reached $11.1 \%$ for lab cells (area $\leq 1 \mathrm{~cm}^{2}$ ) and $8-9.5 \%$ for sub-modules (area $15-30 \mathrm{~cm}^{2}$ ).

\subsection{Design of Dyes for DSCs}

The first stage in the development of dyes has been the identification of functional groups such as $-\mathrm{COOH}$ as a peripheral unit of the bpy ligand, as a key requirement for the dyes to ensure efficient electronic communication between the LUMO of the $\mathrm{Ru}$-dyes and the conduction band of the acceptor titania. Nearly all best perform-

Table 1. Solar conversion efficiency values obtained for some of the 'champion' Ru-polypyridine dyes in DSC using iodide/triiodide as the redox mediator.

\begin{tabular}{|c|c|c|c|c|c|c|c|c|}
\hline Dye & $\begin{array}{l}\text { Abs }[\mathrm{nm}] \\
\& \varepsilon\left[\mathrm{M}^{-1} \mathrm{~cm}^{-1}\right]\end{array}$ & $\begin{array}{l}\text { HOMO } \\
{[\mathrm{V}]}\end{array}$ & $\begin{array}{l}\text { LUMO } \\
\text { [V] }\end{array}$ & $\begin{array}{l}\text { Isc [mA/ } \\
\left.\text { cm }^{2}\right]\end{array}$ & $\begin{array}{l}\text { Voc } \\
{[\mathrm{mV}]}\end{array}$ & FF & $\begin{array}{l}\text { Efficiency } \\
\eta[\%]\end{array}$ & Ref. \\
\hline N719 & $535(14200)$ & +1.12 & & 17.73 & 846 & 0.75 & 11.18 & [1] \\
\hline $\begin{array}{l}\text { N749 } \\
\text { (black } \\
\text { dye) }\end{array}$ & $\begin{array}{l}610 \text { (7500), } \\
536 \text { sh }\end{array}$ & +0.66 & & $\begin{array}{l}20.53 \\
20.90\end{array}$ & $\begin{array}{l}720 \\
736\end{array}$ & $\begin{array}{l}0.70 \\
0.72\end{array}$ & $\begin{array}{l}10.40 \\
11.10\end{array}$ & [2] \\
\hline Z907 & $526(12200)$ & +0.87 & & $\begin{array}{l}13.55 \\
14.60 \\
16.70\end{array}$ & $\begin{array}{l}736 \\
722 \\
753\end{array}$ & $\begin{array}{l}0.70 \\
0.69 \\
0.75\end{array}$ & $\begin{array}{c}7.00 \\
7.30 \\
9.50\end{array}$ & [3] \\
\hline K19 & $543(18900)$ & +0.95 & -0.75 & $\begin{array}{l}13.20 \\
15.10\end{array}$ & $\begin{array}{l}718 \\
747\end{array}$ & $\begin{array}{l}0.745 \\
0.70\end{array}$ & $\begin{array}{l}7.10 \\
8.0\end{array}$ & [4] \\
\hline Z910 & $543(17000)$ & +0.97 & -0.73 & 17.20 & 777 & 0.76 & 10.20 & [5] \\
\hline K51 & & +1.09 & -0.71 & 15.37 & 738 & 0.685 & 7.8 & [6] \\
\hline K68 & $528(11400)$ & +1.02 & -0.68 & 14.40 & 760 & 0.69 & 7.6 & [7] \\
\hline K77 & $546(19400)$ & +0.97 & -0.78 & 19.20 & 780 & 0.725 & 10.50 & [8] \\
\hline K60 & $547(18550)$ & +1.01 & -0.69 & 16.85 & 730 & 0.69 & 8.44 & [9] \\
\hline $\begin{array}{l}\text { CYC- } \\
\text { B11 }\end{array}$ & $554(24200)$ & +0.96 & -0.62 & 20.05 & 743 & 0.77 & 11.50 & [10] \\
\hline C101 & $547(17500)$ & +0.90 & -0.70 & 17.94 & 778 & 0.785 & 11.0 & [11] \\
\hline $\begin{array}{l}\mathrm{Ru}\left(\mathrm{F}_{2}-\right. \\
\text { phpy) } \\
(\mathrm{dcbpy})_{2}\end{array}$ & 490,560 & +1.08 & -0.76 & 17.10 & 800 & 0.74 & 10.10 & [12] \\
\hline
\end{tabular}

ing dyes for DSC identified till date have one such 'anchoring group'. In one series of studies, a number of mixed ligand complexes of the type $\left[\mathrm{Ru}(\mathrm{dc}-\mathrm{LL})_{2}(\mathrm{X})_{2}\right]$ and $\left[\mathrm{Ru}(\mathrm{tc}-\mathrm{LLL})(\mathrm{X})_{3}\right]$ (where LL and LLL are bidentate bipyridine and tridentate terpyridine ligands and $\mathrm{X}$ is a non-chromophoric donor or acceptor ligand) have been synthesized and their performance examined in DSCs. One monodentate donor ligand (X) which has been found to be very effective is thiocyanate $(-\mathrm{SCN})$. Ru-complexes N3/N719 and N749 (also known as black dye) are best performing dyes designed as per the above scheme (Table 1). Certified conversion efficiency of $11.1 \%$ has been obtained with these dyes. Numerous laboratories across the globe use these dyes as a standard dye in DSC development studies.

A notable feature of the mesoporous films is the enormous surface area available for dye deposition (1000 fold higher as compared to the geometric area) and major part of the $\mathrm{TiO}_{2}$ surface is filled with $-\mathrm{OH},-\mathrm{O}-$ and $-\mathrm{OH}_{2}{ }^{+}$surface groups. It has been found that exposure of $\mathrm{TiO}_{2}$ films to excess humidity (moisture) leads to uptake of water molecules. Presence of water in the pores causes DSC to take a long time to give stable output at somewhat reduced efficiency. For this reason, it was decided to increase the hydrophobic character of the dye by attaching a long alkyl chain as a peripheral substituent. Studies with $\mathrm{Ru}-$ dyes such as $\left.\mathrm{Ru}(\mathrm{dcbpy}-\mathrm{R})_{2}(\mathrm{NCS})_{2}\right], \mathrm{R}=$ $\mathrm{C}_{9} \mathrm{H}_{19}$ (known as Z907 dye, Table 1) have shown that the thermal and photochemical stability of the DSC is dramatically improved. For large area terrestrial applications, solar cells have to satisfy several stringent tests, including thermal stability (up to $80^{\circ} \mathrm{C}$ ) and photochemical stability ('light soaking') for exposure up to 1000 h. DSCs based on Ru-dyes carrying long alkyl chain satisfy these requirements. In another extension, numerous Ru-dyes carrying poly(oxyethylene) side chains have been examined (dye such as K51, K68, Table 1). Li-ions present in the electrolytes are intercalated in the pores and presence of poly(oxyethylene) groups on the dye reduce such processes, leading to better overall performance.

Reduced mobility of the charge carriers in the oxide film along with reduced amount of dye uptake in thinner films leads to overall solar conversion efficiency of only 4-6\% for SS-DSC systems. Improvement in the solar conversion efficiency should be possible if the molar absorbance of the Ru-dyes can be improved. Possible ways in which the $\pi$-system of the polypyridine ligands can be improved are through introduction of unsaturated (ethylene/vinylene) bonds. Indeed, Ru-dyes with such modifications (dyes such as Z910, K60, K68, K73, K77, Table 1) show higher molar absorbance as compared to their parent analogs. Based on the dramatic improvement in molar absorbance of organic chromophore such as triphenylamine and difluorenyl dyes, Ru-dyes have been synthesized incorporating unsaturated units such as 'thiophene'. C-series of Ru-dyes (dyes such as C101, C102, C103, C104 (Table 1) developed in collaboration with 
Peng Wang and coworkers) indeed show much higher molar absorbance. The thiophene moieties attached to the ancillary bipy-ligand enhance the light-harvesting capacity of these complexes by increasing their extinction coefficient and shifting their spectral response to the red. With C101 and CYC B11 dyes incorporating thiophene antenna units, the MLCT band in the visible region is shifted from 530 to $553 \mathrm{~nm}$ and the extinction coefficient is increased from 14500 to $24200 \mathrm{M}^{-1} \mathrm{~cm}^{-1}$. A two-fold increase in molar absorbance permits usage of thinner films of $\mathrm{TiO}_{2}$ resulting in higher Voc values, due to a decrease in the dark current and an increase in the electron concentration in the mesoporous films. With thinner films, electrolyte resistance and diffusion overvoltage for the triiodide reduction decreases, leading to higher fill factor (ff). With these improvements, DSC efficiency for lab cells have crossed the $12 \%$ benchmark.

Three key types of structural modifications mentioned above (introduction of anchoring ligands, $\pi$-conjugation increasing antenna units, donor ligands) has led to a generalized overall design strategy of dyes for use in DSCs. These dyes contain an electron donor (D) and acceptor (A) moiety, constituted typically by an arylamine and a cyanoacrylate group, respectively, which are connected via one or several thiophene moieties acting as a $\pi$-conducting bridge. Structures of this kind will be abbreviated below as $D-\pi-A$ dyes. The sensitizer is attached to the surface of the mesoscopic titania film via the cyanoacrylate group that binds it coordinatively to the surface Ti(IV) ions. In addition to metal complexes based on polypyridine ligands, metalloporphyrins, metallophthalocyanines and numerous organic dyes (indolines, coumarins, difluorenyl, squaraines,...) have been modified to incorporate these key functional elements as part of the dye. A number of triphenylamine- and difluorenyl chromophore-based organic dyes have been designed which show remarkably high solar-to-electrical conversion efficiency of $>10 \%$.

\subsection{Electrolytes and Redox Mediators}

It was mentioned earlier that a mixture of iodine and iodide in a low viscosity solvent such as acetonitrile is often used as the standard redox electrolyte in DSC studies. With a redox potential of $+0.50 \mathrm{~V}$ vs. NHE, it is ideally placed for most of the dyes examined till date to deliver Voc values in the range of $600-800 \mathrm{mV}$. The $\mathrm{I}_{3}{ }^{-} / \mathrm{I}^{-}$system has the advantage that the loss of photo-injected electrons by electron transfer to $\mathrm{I}_{3}^{-}$from the mesoporous $\mathrm{TiO}_{2}$ is relatively slow, probably as a consequence of the fact that the reaction involves the transfer of two electrons and the breaking of the I-I bond. At the same time, regeneration of $\mathrm{I}^{-}$ions at the cathode in the DSC is fast, since a platinum catalyst that breaks the I-I bond by chemisorption is used. As a consequence, voltage losses at the cathode are minimized. However iodide-triiodide redox couple also has practical limitations.

Significant light absorption in the blue light region and corrosive nature of the electrolyte diminish their utility. There have been numerous attempts to find better alternatives. Suggested alternatives to $\mathrm{I}_{3}{ }^{-/ \mathrm{I}^{-}}$ include a range of cobalt complexes, the disulfide/thiolate system, and the $\mathrm{Ni}$ (III)/ (IV) bis(dicarbollide) system.

Polypyridine complexes of cobalt have the potential to yield much higher photovoltages due to deeper location of the redox potential of the $\mathrm{Co}(\mathrm{II}) / \mathrm{Co}(\mathrm{III})$ couple. Several Co-complexes have been studied in dye-sensitized cells as well as in solar cells sensitized by nanoparticles of inorganic semiconductors such as $\mathrm{CdSe}, \mathrm{CdS}$, and $\mathrm{PbS}$. Simple 2,2'-bpy or 1,10 phencomplexes exhibit slower dye reduction rates and faster recombination with photoinjected electrons, leading to poor fill factors. A study using the [Co(dbbip) $)_{2}$ (dbbip = 2,6-bis (1'-butylbenzimidazol-2'-yl) pyridine) redox couple confirms that the electron diffusion length in DSC is reduced substantially when the conventional $\mathrm{I}_{3}{ }^{-} / \mathrm{I}^{-}$ electrolyte is replaced by the $\mathrm{Co}$ (III)/Co(II) complex. A Co-complex with sterically hindering peripheral tert-butyl groups, Co $(D T B)_{3}^{3 / 2+}$ complex, (DTB) 4,4'-di-tertbutyl-2,2'-bipyridine showed better performance. Use of a blocking layer on the conducting glass reduces any shunting via electron transfer from the substrate under load conditions. Significant increase in the overall conversion efficiency has been obtained in the presence of phenothiazine (PTZ) or ferrocene (Fc), both of which have a small reorganizational energy associated with the electron transfer.

A new disulfide/thiolate redox couple that has negligible absorption in the visible spectral range has been found to give an unprecedented efficiency of $6.4 \%$ under standard illumination test conditions in sensitized heterojunction solar cells. The redox couple $\left(\mathrm{T}_{2} / \mathrm{T}^{-}\right)$, where $\mathrm{T}^{-}$represents the 5-mercapto-1-methyltetrazole ion and $\mathrm{T}_{2}$ stands for its dimer, has redox potential $0.485 \mathrm{~V}$ vs. NHE, a value close to that of the $\mathrm{I}_{3}{ }^{-} / \mathrm{I}^{-}$redox couple. A double layer mesoporous titania film based DSC with $\mathrm{T}^{-} / \mathrm{T}_{2}$ mixture along with $\mathrm{TBP}$ and $\mathrm{LiClO}_{4}, 11+5$ $\mu \mathrm{m} \mathrm{TiO}_{2}$ gave an overall conversion efficiency of $6.44 \%$ at 1 sun and $8.14 \%$ at 0.1 Sun solar radiation. To our knowledge, this is the highest power-conversion efficiency under full sunlight conditions reported for a DSC that does not use $\mathrm{I}_{3}^{-} / \mathrm{I}^{-}$as a redox mediator. In similar studies, a radical cat- ion redox mediator TEMPO (2,2,6,6-tetramethyl-1-piperidinyloxy radical) has also been found to be efficient. To make a redox couple, $\mathrm{NOBF}_{4}$ was added to oxidize 10 mol\% of TEMPO to TEMPO ${ }^{+}$.

\subsection{Robust Electrolytes Based on Ionic Liquids}

A key problem with solvents such as $\mathrm{CH}_{3} \mathrm{CN}$ is their low boiling point and high vapor pressure. If the sealed DSC is heated to temperatures $\geq 60{ }^{\circ} \mathrm{C}$, the internal vapor pressure of the cell increases significantly and the solvent vapor becomes corrosive causing a decrease in the cell performance (bringing the sealants into the electrolyte). To some extent this problem can be reduced using a high-boiling solvent such as 3-methoxy propionitrile (MPN). Enormous research effort is being put in to find suitable electrolytes for outdoor terrestial application of dye-sensitized solar cells. Ionic liquids such as asymmetrical dialkyl imidazolium salts are being examined mainly due to their very low vapor pressures. The viscosity of most of the ionic liquids however is high, with some tunability feasible with change of alkyl chain length and counterions. After testing, numerous combinations of different ionic liquids have been found to give optimal solar conversion efficiency, preserving the required thermal stability ( $\mathrm{T}$ $\geq 80^{\circ} \mathrm{C}$ ). Due to the higher viscosity of these mixtures, the solar conversion efficiency obtained is a few percent below than that obtained with neat solvents such as acetonitrile. A eutectic mixture of three different ionic liquids without volatile nitrile solvent ('solvent-free electrolyte') has also been developed for use with iodide-based redox systems.

\subsection{Improving the Photoanode and Light-absorption Properties}

Using suitable synthetic procedures it is possible to fabricate titania films with varying light scattering properties, from totally translucent to highly scattering white layers. It turns out that for nearly all the light absorbers examined up to now, light absorption in the visible-near IR region is limited to $c a$. $300 \mathrm{~nm}$ bandwidth. By variation of the nature of the main delocalized $\pi$-chromophoric system and donor or acceptor ligands, it is possible to tune the spectral absorption range through the 400-1200 nm window. Dyes that absorb strongly in the blue-green region (most organic dyes) do not absorb much light in the low energy red/near-IR region. With metalloporphyrins and phthalocyanines the reverse situation prevails. As a consequence, maximum solar light to electrical conversion efficiency has been limited to the $8-10 \%$ range. Most metal complexes show a long absorption tail in the red region and here 'modulation' of the light 
scattering properties of the mesoporous oxide layer can improve significantly the overall electric power conversion. For example, using 200-400 $\mathrm{nm}$ sized anatase particles as light scattering centers increases the Isc of N719-based DSCs by as much as $3-4 \mathrm{~mA} / \mathrm{cm}^{2}$ because of the enhanced absorption of red or near-infrared photons. Similarly post-treatment of the particles with a $\mathrm{TiCl}_{4}$ (aq.) has been found to improve DSC performance.

Researchers at Sharp for example have shown that for the standard 'black dye/ N749', the overall solar conversion efficiency can be improved to $>11 \%$ upon introduction of suitable scattering layers. Amorphous precursor $\mathrm{TiO}_{2}$ beads synthesized using a sol-gel process in the presence of hexadecylamine similarly improves the solar energy conversion. In another research effort various rare-earth doped titania films have been studied. $\mathrm{Ga}^{3+}, \mathrm{Y}^{3+}$ doped titania anodes have been found to be efficient photoanodes. The improvement in performance was ascribed to an increase of electron lifetime in the new photoanodes, which affords close to unity charge collection efficiency.

There have been a number of studies varying the morphology of the oxide substrate as well. A whole range of nanostructures has been tested thus far, ranging from simple assemblies of nanoparticles to nanorods and nanotubes. These studies are motivated by the expectation that the transport of charge carriers along the tubes is more facile than within a random network of nanoparticles, where the electrons have to cross many particle boundaries. Hence, one-dimensional nanostructures should produce a lower diffusion resistance than the nanocrystalline films facilitating the collection of photogenerated charge carriers.

\subsection{Counter Electrodes for DSC}

In the standard design of the liquidelectrolyte based DSCs, deposits of finely divided Pt-particles on transparent conducting oxide (TCO) are used as the cathode. Screen printing pastes have been developed that permit rapid doctor-blading or screen-printing of Pt-layers on TCO at various loading levels. In view of the high cost of $\mathrm{Pt}$, there have been numerous attempts to find other alternatives for the cathode. Various allotropes of carbon (such as Glassy C, amorphous C, graphite, fullerenes, carbon nanotubes CNT and graphenes) have been examined as possible candidates with promising results. Commercial graphene nanoplatelets in the form of optically transparent thin films on F-doped $\mathrm{SnO}_{2}$ (FTO) exhibited high electrocatalytic activity toward the $\mathrm{I}_{3}^{-} / \mathrm{I}^{-}$redox couple, particularly in electrolyte based on ionic liquid (Z952).
Being powders and difficult to form, multiwall carbon nanotubes (MWNTs) cannot be made into solar cell counter electrodes unless they are dispersed into a matrix polymer. Also MWNTs tend to aggregate and are difficult to disperse, even with the use of organic solvents. Ionic liquids have been used to modify the surface of MWNTs. CoS deposited on ITO/PEN substrate is also used as a counter electrode of DSC. CoS is very effective in catalyzing the reduction of triiodide to iodide in a DSC. Various conducting polymers have also been studied. PEDOT:PSS, a conducting polymer that has a thiophene skeleton and exhibits hydrophilicity in a pair with sulfonate.poly (3,4-ethylenedioxythiophe ne):poly(styrenesulfonate) widely used in bulk heterojunction solar cells has been found to be very efficient as a counter electrode for DSC. Similarly efficient DSCs are based on poly $(3,4-$ ethylenedioxythiophene) counter electrode derived from ionic liquids.

\section{Photochemical Water Splitting}

In addition to direct conversion of solar energy to electricity, photo-assisted production of energy-rich products has also been examined for many years. Decomposition of water to its constituent molecules $\mathrm{H}_{2}$ and $\mathrm{O}_{2}$ using sunlight is attractive for several reasons: i) it is a key reaction of natural photosynthesis by which nature fixes $\mathrm{CO}_{2}$ to carbohydrates and releases oxygen in its place; ii) water itself does not absorb visible light and hence water-splitting needs to be sensitized using dyes that absorb visible light and iii) formation of molecular oxygen and hydrogen involve multi-electron transfer in a concerted manner while all photoredox reactions of simple molecules and metal complexes involve only 1-e-transfer:

$$
\begin{aligned}
& 2 \mathrm{H}_{2} \mathrm{O}(l) \rightarrow \mathrm{O}_{2}(g)+4 \mathrm{H}^{+}(a q)+4 \mathrm{e}^{-} \\
& \left(\mathrm{E}^{\mathrm{o}}{ }_{\mathrm{ox}}=-1.23 \mathrm{~V}\right)
\end{aligned}
$$

$$
\begin{aligned}
& 2 \mathrm{H}^{+}(a q)+2 \mathrm{e}^{-} \rightarrow \mathrm{H}_{2}(g) \\
& \left(\mathrm{E}_{\text {red }}^{\mathrm{o}}=0.00 \mathrm{~V}\right)
\end{aligned}
$$

There have been many attempts to mimic the role of enzymes which catalyze these multi-electron transfer using simple complexes and colloidal metal/metal oxide redox catalysts.

Electrolysis of water can be achieved with minimal overvoltage using catalytic electrodes such as $\mathrm{Pt}$ for $\mathrm{H}_{2}$ evolution in the cathode and a metal oxide such as $\mathrm{RuO}_{2}$ or $\mathrm{IrO}_{2}$ for the oxidation process at the anode. Following the pioneering report of Fujishima and Honda on photochemical water splitting in photoelectrochemical cells based on $\mathrm{TiO}_{2}$ semiconductor electrodes, there have been numerous studies attempting to identify best candidates. In 'photoelectrochemical solar cells' irradiation of semiconductors leads to production of charge carriers, electrons (e-) and holes $(h+)$. These charge carriers are subsequently used to effect water splitting reactions cited above. An important additional requirement is that the chemical (Fermi) potentials of electrons and holes are suitably based with respect to chemical potentials required for water oxidation and reduction (1.23 and $0 \mathrm{~V}$ vs. NHE) respectively.

Only titania and some titanates such as $\mathrm{SrTiO}_{3}$ satisfy this requirement. Unfortunately their bandgap is $\geq 3.2 \mathrm{eV}$ so that only a small fraction of solar radiation can be utilized. Compound semiconductors of the II-IV and III-V families such as $\mathrm{InP}(\mathrm{Eg}=1.3 \mathrm{eV})$ have smaller bandgaps and appropriate energy levels; however, they exhibit poor stability in aqueous environments. Two semiconducting oxide materials $\mathrm{WO}_{3}$ and $\mathrm{Fe}_{2} \mathrm{O}_{3}$ are important in this context due to their relatively smaller bandgap $2.5 \mathrm{eV}$ range. A major limitation of these materials is the low mobility of holes within the bulk of the semiconductor. Most of the photogenerated charge carriers recombine before reaching the electrolyte interface and hence poor photoelectric conversion is obtained even with the single crystal form of the semiconductor. A second factor that limits efficiency of water splitting is the poor catalytic response of these materials for the two multi-electron transfer reactions.

Application of nanostructuring techniques and advanced interfacial engineering can provide significant improvement in the performance of these photoanodes. Landmark improvements in the performance indeed have been obtained using mesoporous films of $\mathrm{WO}_{3}$ and hematite $\left(\alpha-\mathrm{Fe}_{2} \mathrm{O}_{3}\right)$ photoanodes. Morphological control of the oxide layers along with appropriate surface treatment of the layers can address some of the inherent limitations of these materials. The treatment of $\mathrm{Fe}_{2} \mathrm{O}_{3}$ photoanodes (prepared by a CVD method) with a monolayer of $\mathrm{Co}^{2+}$ complexes for example, results in $c a .0 .1 \mathrm{~V}$ reduction of the photocurrent onset potential. Atmospheric pressure chemical vapor deposition APCVD methods have been used to fabricate cauliflower-like structures of hematite and such materials have exhibited record efficiency for photoelectrolysis of water. After coating these films with a layer of $\mathrm{IrO}_{2}$ nanoparticles to reduce the overpotential for water oxidation, photocurrent densities greater than $3 \mathrm{~mA} / \mathrm{cm}^{2}$ at $1.23 \mathrm{~V} \mathrm{NHE}$ and stan- 
dard illumination conditions have been demonstrated.

Tungsten oxide has a bandgap of $2.6 \mathrm{eV}$ but has its conduction band-edge too low in energy to reduce water directly. Reduction of water however can be achieved upon application of additional electrical bias voltage in the range of $200-300 \mathrm{mV}$. It turns out that a tandem photovoltaic solar cell-water splitting cell can be designed in which a photovoltaic device such as DSC can be used to generate the required bias voltage using the solar photons not absorbed by the semi-transparent photoanode. Using such a tandem design with a $\mathrm{WO}_{3}$ photoanode, complete water decomposition to $\mathrm{H}_{2}$ and $\mathrm{O}_{2}$ has been demonstrated with an overall water splitting efficiency of $4.5 \%$. Unfortunately due to its relatively large bandgap and expected kinetic losses, a maximum of only $8 \% \mathrm{STH}$ is possible with $\mathrm{WO}_{3}$.

\section{Materials Design for Organic Light Emitting Diodes}

A remarkable advancement of the past decade is identification of several transition metal complexes exhibiting extremely intense luminescence at ambient temperatures. Most often the one-electron potentials for oxidation and reduction are such that the recombination of them leads to population of the lowest electronically excited state, accompanied by luminescence. Such complexes have the potential as substrates for light-emitting diodes LEDs. For practical applications such materials have to meet several requirements: ease of material processing, pure color emission in the red, green or blue RGB with high luminosity yields, and stability over extended redox cycling.

Cyclometallated iridium(III) complexes have been found to be ideal candidates due to their high emission quantum efficiency, tunable emission color over the entire visible spectrum, and chemical stability. These compounds are suitable for a wide range of applications such as oxygen sensors, biological labeling agents, photocatalysts for hydrogen production, sensitizers for solar cells, and as dopants for organic light-emitting devices. These complexes exhibit highest efficiency for triplet emission ( $>0.6$ at RT) for several reasons: i) large d-orbital splitting compared to other transition metals; ii) strong ligand field strength of the ph-py ligand increases the $d$ orbital splitting leading to an enlarged gap between the eg orbital of Ir and LUMO of the ligand and iii) close-lying $\pi-\pi^{*}$ and MLCT transitions.

Two designs have been mainly used to prepare new cyclometallated iridium(III) phosphorescent emitters. The first design is the tris-homoleptic cyclometallated iridium(III) complex, $\operatorname{Ir}(\mathrm{LL}){ }_{3}^{3+}$. The second important design has the general formula $\left[\operatorname{Ir}(\mathrm{C} \cap \mathrm{N})_{2}(\mathrm{~L})\right]$ where $\mathrm{L}$ is again a monoanionic bidentate ligand, but different from the $\mathrm{C} \cap \mathrm{N}$ ligand. Other ligands such as acetylacetonate $(\mathrm{O} \cap \mathrm{O})$ or picolinate type $(\mathrm{O} \cap \mathrm{N})$ type of ligands can also be used. This design is advantageous because the compounds are obtained using a synthesis with softer conditions. Mixed ligand (heteroleptic) complexes can usually be obtained by reacting the chloro-bridged dimer in low boiling solvents like dichloromethane. A second advantage is the increased possibility of tuning the properties of the iridium complex, as two different ligand types are accessible for substitution. Using those two designs, enormous progress has been made over the last decade leading to devices with very high efficiencies.

\section{Acknowledgements}

With immense gratitude and pleasure we acknowledge generous funding for our research by various national and international agencies and industrial houses. We thank in particular the following for their current/recent support: Swiss National Funds for Scientific Research, OFEN, European Union FP7 funding through ROBUST DSC, NanoPEC, INNOVASOL, KAUST, ORION, MOLESOL, ESCORT, SANS projects, COST D35 Action program and Marie-Curie Intra-European Fellowships. International collaboration with several academic and industrial laboratories within and outside Europe has also been very beneficial in advancing our research.

Received: August 5, 2011

[1] M. K. Nazeeruddin, S. M. Zakeeruddin, R Humphry-Baker, M. Jirousek, P. Liska, N. Vlachopoulos, V. Shklover, C. H. Fischer, M Grätzel, Inorg. Chem. 1999, 38, 6298.

[2] M. K. Nazeeruddin, P. Pechy, T. Renouard, S M. Zakeeruddin, R. Humphry-Baker, P. Comte, P. Liska, Le Cevey, E. Costa, V. Shklover, L. Spiccia, Glen B. Deacon, A. Bignozzi, M Graetzel, J. Am. Chem. Soc. 2001, 123, 1613

[3] D. Kuang, P. Wang, S. Ito, S. M. Zakeeruddin, M. Graetzel, J. Am. Chem. Soc. 2006, 128, 7732; P. Wang, B. Wenger, R. Humphry-Baker, J.-E. Moser, J. Teuscher, W. Kantlehner, J Mezger, E. V. Stoyanov, S. M. Zakeeruddin, M Graetzel, J. Am. Chem. Soc. 2005, 127, 6850.

[4] D. Kuang, S. Ito, B. Wenger, C. Klein, J.-E Moser, R. Humphry-Baker, S. M. Zakeeruddin, M. Grätzel, J. Am. Chem. Soc. 2006, 128, 4146 P. Wang, C. Klein, R. Humphry-Baker, S. M. Zakeeruddin, M. Grätzel, Appl. Phys. Lett. 2005, 86, 123508

[5] P. Wang, S. M. Zakeeruddin, J.-E. Moser, R Humphry-Baker, P. Comte, V. Aranyos, A. Hagfeldt, M. K. Nazeeruddin, M. Graetzel, $A d v$. Mater. 2004, 16, 1806.

[6] D. Kuang, S. Ito, B. Wenger, C. Klein, J.-E Moser, R. Humphry-Baker, S. M. Zakeeruddin, M. Graetzel, J. Am. Chem. Soc. 2006, 128, 4146.

[7] D. Kuang, C. Klein, H. J. Snaith, J.-E. Moser, R Humphry-Baker, P. Comte, S. M. Zakeeruddin, M. Grätzel, Nano Lett. 2006, 6, 769.
[8] D. Kuang, C. Klein, S. Ito, J.-E. Moser, R. Humphry-Baker, N. Evans, F. Duriaux, C. Grätzel, S. M. Zakeeruddin, M. Grätzel, $A d v$. Mater. 2007, 19, 1133.

[9] D. Kuang, C. Klein, S. Ito, J.-E. Moser, R. Humphry-Baker, S. M. Zakeeruddin, M. Grätzel, Adv. Funct. Mater. 2007, 17, 154.

[10] C.-Y. Chen, M. Wang, J.-Y. Li, N Pootrakulchote, L. Alibabaei, C. Ngoc-le, J.-D. Decoppet, J.-H. Tsai, C. Graetzel, C.-G. Wu, S. M. Zakeeruddin, M. Grätzel, ACS Nano 2009, 3, 3103 .

[11] F. Gao, Y. Wang, D. Shi, J. Zhang, M. Wang X. Jing, R. Humphry-Baker, P. Wang, S. M. Zakeeruddin, M. Grätzel, J. Amer. Chem. Soc. 2008, 130, 10720.

[12] T. Bessho, E. Yoneda, J. H. Yum, M. Guglielmi, I. Tavernelli, H. Imai, U. Rothlisberger, M. K Nazeeruddin, M. Grätzel, J. Am. Chem. Soc. 2009, 131, 5930 .

\section{References for further reading:}

'Dye Sensitized Solar Cells', Ed. K. Kalyanasundaram, EPFL Press, Lausanne, 2010.

A. Hagfeldt, G. Boschloo, L. Sun, L. Kloo, H. Pettersson, Chem. Rev. 2010, 110, 6595 .

S. M. Zakeeruddin, M. Grätzel, Adv. Funct. Mater 2009, 19, 1.

J.-H. Yum, E. Baranoff, S. Wenger, M. K. Nazeeruddin, M. Graetzel, in 'Energy \& Environmental Science', vol. 4, 2011, pp. 842-857.

A. Mishra, M. K. R. Fischer, P. Bäuerle, Angew. Chem. Int. Ed. 2009, 48, 2474.

M. Gorlov, L. Kloo, Dalton Trans. 2009, 2655.

Materials for OLED

H. J. Bolink, F. De Angelis, E. Baranoff, C. Klein, S. Fantacci, E. Coronado, M. Sessolo, K. Kalyanasundaram, M. Graetzel, M. K. Nazeeruddin, Chem. Commun. 2009, 4672

E. Baranoff, S. Fantacci, F. De Angelis, X. Zhang, R. Scopelliti, M. Graetzel, M. K. Nazeeruddin, Inorg. Chem. 2011, 50, 451 and references cited therein.

E. Baranoff, H. J. Bolink, F. De Angelis, S. Fantacci, D Di Censo, K. Djellab, M. Grätzel, M. K. Nazeeruddin, Dalton Trans. 2010, 39, 8914

Photodecomposition of Water

A. Fujishima, K. Honda, Nature 1972, 238, 37

M. Grätzel, Acc. Chem. Res. 2009, 42, 1788.

B. O'Regan, J. R. Durrant, Acc. Chem. Res. 2009, 42, 1799.

K. Kalyanasundaram, M. Grätzel, in 'Current Opinion In Biotechnology', vol. 21, 2010, p. 298.

M. G. Walter, E. L. Warren, J. R. McKone, S. W. Boettcher, Q. Mi, E. A. Santori, N. S. Lewis, Chem. Rev. 2010, 110, 6446.

T. R. Cook, D. K. Dogutan, S. Y. Reece, Y. Surendranath, T. S. Teets, D. G. Nocera, Chem. Rev. 2010, 110, 6474. F. Jiao, H. Frei, Energy Environ. Sci. 2010, 3, 1018 J. J. Concepcion, J. W. Jurss, M. K. Brennaman, P. G. Hoertz, A. O. T. Patricinio, N. Y. Murakami Iha, J. L. Templeton, T. J. Meyer, Acc. Chem. Res. 2009, 42, 1954.

W. J. Youngblood, S-H. Anna Lee, K. Maeda, T. E. Mallouk, Acc. Chem. Res. 2009, 42, 1966.

D. Gust, T. A. Moore, A. L. Moore, Acc. Chem. Res. 2009, 42, 1890.

P. V. Kamat, K. Tvrdy, D. R. Baker, J. G. Radic, Chem Rev. 2010, 110, 6664

I. Cesar, K. Sivula, A. Kay, R. Zboril, M. Grätzel, J. Phys. Chem. C 2009, 113, 772

A. Duret, M. Grätzel, J. Phys. Chem. B 2005, 109, 17184

A. Kay, I. Cesar, M. Grätzel, J. Am. Chem. Soc. 2006, 128,15714

K. Sivula, J. Brillet, M. Grätzel, Proc. SPIE 2010, 7770, 77700G

K. Sivula, F. Le Formal, M. Grätzel, Chem. Mater. 2009, 21, 2862

F. Le Formal, M. Graetzel, K. Sivula, Adv. Funct. Mater. 2010, 20, 1099

D. K. Zhong, M. Cornuz, K. Sivula, M. Grätzel, D. R. Gamelin, Energy \& Environ. Sci. 2011, 4, 1759 